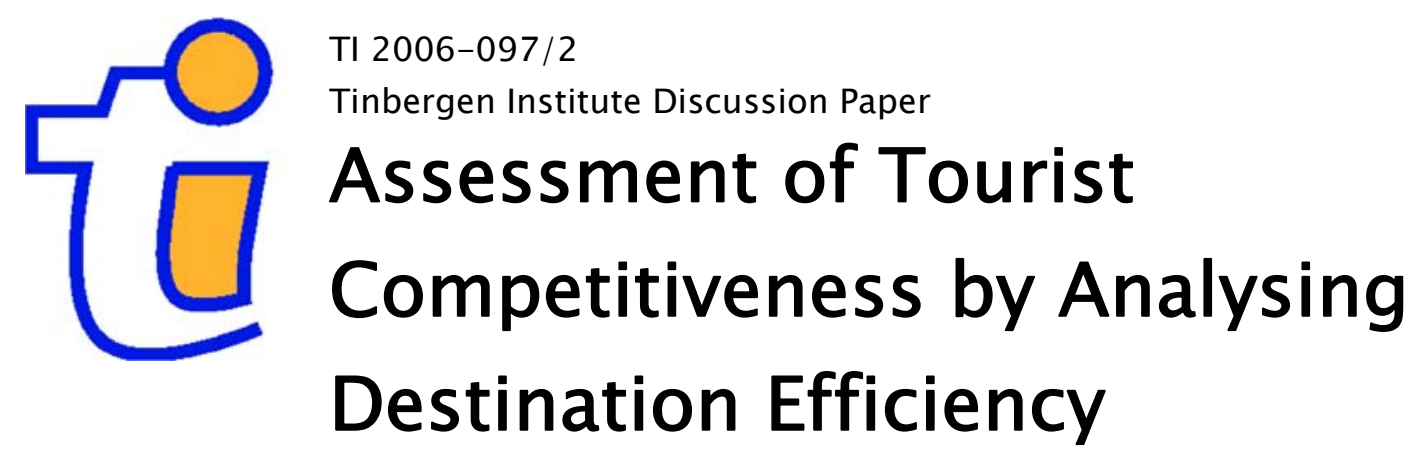

\author{
M. Francesca Cracolicia,b \\ Peter Nijkamp p,c \\ Piet Rietveldb,c
}

a University of Palermo;

b Vrije Universiteit Amsterdam;

c Tinbergen Institute. 


\section{ASSESSMENT OF TOURIST COMPETITIVENESS BY ANALYSING DESTINATION EFFICIENCY*}

M. Francesca Cracolici ${ }^{\mathrm{a}, \mathrm{b}}$, Peter Nijkamp ${ }^{\mathrm{b}}$ and Piet Rietveld ${ }^{\mathrm{b}}$

${ }^{\mathrm{a}}$ Department of National Accounting and Analysis of Social Processes University of Palermo

V.le delle Scienze Ed. 2

90133 Palermo, Italy

${ }^{\mathrm{b}}$ Department of Spatial Economics

Free University

De Boelelaan 1105

1081 HV Amsterdam, The Netherlands

* Correspondence:

cracolici@unipa.it (M.F. Cracolici); pnijkamp@feweb.vu.nl (P. Nijkamp); prietveld@feweb.vu.nl (P. Rietveld). 


\title{
ASSESSMENT OF TOURIST COMPETITIVENESS BY ANALYSING DESTINATION EFFICIENCY
}

\begin{abstract}
Recently the notion and the measurement of destination competitiveness have received increasing attention in the economics literature on tourism. The reason for this interest emerges from both the increasing economic importance of the tourist sector and the increasing competition on the tourist market as a consequence of the transition from mass tourism to a new age of tourism that calls for a tailor-made approach to the specific attitudes and needs of tourists. The central subject of this paper - inspired by the conceptual competitiveness model developed earlier by Crouch and Ritchie - concerns the efficiency of tourist site destinations. Using a dataset of 103 Italian regions for the year 2001, an economic efficiency analysis based on a production frontier approach has been made in the present study. The study deploys a measure of tourist site competitiveness in terms of its technical efficiency using parametric and non-parametric methods, a stochastic production function and data envelopment analysis, respectively.
\end{abstract}




\section{Competition in the Tourist Sector}

Tourism is a rapidly emerging new economic sector in a globalizing world. The number of competing tourist destinations is vast and prompts fierce competition by alternative tourist sites. The question is then: who will be the winner in this competitive game?

This paper aims to assess production frontiers and efficiency coefficients for alternative tourist destination sites. Efficient operations of tourist sites are important in order to maintain or gain a national or/and international market share in tourism. The choice behaviour of modern tourists is sometimes volatile and unpredictable. The life-cycle, in the long run, of the tourist destination product in a certain area depends largely on the ability to efficiently combine and manage inputs to produce given output targets in tourism. Thus, a region may be regarded as a firm that tries to attract a maximum share of tourist demand (national and international) through an efficient combination of input resources.

If the tourist territory is analysed as if it were a commercial company, then we can hypothesize that a tourist area should be able to manage its input efficiently; in other words, the territory's physical and human resources constitute the input of a (virtual) tourist 'production process', and the output is then formed by arrivals, bed-nights, value added, employment, customer satisfaction, etc. As a consequence, tourist destination performance can be evaluated through the measurement of its efficient resource use. A relevant territory can then evaluate its tourist performance by assessing its efficiency, thus allowing tourist destination managers to identify and check any process dysfunctions in a given area in order to define strategic and operational actions for effective tourism policy.

An efficient performance at regional level, which is what motivates the present study, can thus be assessed on the basis of an analysis of destination competitiveness.

In the light of the above considerations, the tourist site's production technology can be characterised by a production function, which provides the maximum possible output (i.e., output target), given the proper inputs. When a tourist site is not able to produce the maximum possible output, given the inputs, the tourist site is inefficient and will attract relatively less tourists compared to competing areas. The reason may be that too many inputs are used, an imbalance between inputs and outputs exists, and/or the input combination is not optimal. This may be caused by various deficiencies. Firstly, the destination management organizations (DMOs) may hold the opinion that the tourist site concerned is in the growth or maturity phase of the tourist product life-cycle (Prosser, 1994), while this is actually not the case; as a consequence, DMOs may then be inclined to support tourist investments, thereby increasing the imbalance between inputs and outputs. Secondly, the tourist site is in the growth or maturity phase of the tourist product life-cycle, but DMOs make insufficient efforts to maintain, in the long run, its market position. Thirdly, an imbalance between inputs and 
outputs may be due to uncontrollable factors or unexpected events that do not allow the tourist site to achieve its optimal output (i.e., the production frontier). Finally, different tourist areas may have a different production process of efficiency. For instance, tourist coastal sites may have a higher efficiency than artistic-cultural areas (or mountainous and lake destinations). Besides, sites without a prevalent tourist function may have an inferior (or higher) efficiency than conventional tourist function sites. This heterogeneity, which is evident among various Italian regions, has to be recognised in empirical analysis.

In brief, a tourist site can be inefficient for several reasons:

1. governmental regulations may limit capacity utilisation (e.g., a limit on the construction of hotels, transport infrastructures, etc.);

2. global forces (e.g., increasing attention for the natural environment; a profound restructuring of economies occurring worldwide; shifting demographic patterns in global markets; the increasingly complex technology-human resource interface, etc.) (see Crouch and Ritchie, 1999) may influence the outcomes of strategic and operative marketing actions;

3. physiography, culture and social forces (e.g., environmental limits, well-being of local residents, etc.) may limit the operations in a tourist area.

The central question in this paper - in the competitive advantage context (for details, see Porter, 1990; and Crouch and Ritchie, 1999) - is whether tourist destinations operate efficiently, i.e., are able to deploy the inputs at their disposal in an efficient manner in order to attract a maximum share of tourist demand and to be competitive against key competitors.

Regions are considered in our paper as heterogeneous multi-product, multi-client business organisations. In the light of the competitive behaviour on the tourism market, they have to maximize their market share given the available resources. Consequently, traditional industrial choice models (such as frontier analysis) may be applied to this sector as well ${ }^{1}$. We will offer a concise illustrative summary of business models used in the tourism sector.

In the tourism literature the analysis of efficiency is restricted to a small number of studies, which limit the analysis to micro-units (e.g. hotels, corporate travel department and etc.). Among the earliest, Morey and Dittman (1995) - using data envelopment analysis with 7 inputs and 4 outputs - evaluated the general-manager performance of 54 hotels of an American chain - geographically dispersed over the continental United States - for the year 1993.

Hwang and Chang (2003), using data envelopment analysis and the Malmquist productivity index, measured the managerial performance of 45 hotels in 1998 and the efficiency change of 45 hotels from 1994 to 1998. They found there was a significant

\footnotetext{
${ }^{1}$ In recent years, several regional applications of frontier analysis have emerged; see Macmillan (1986); Charnes et al. (1989); Susiluoto and Loikaanen (2001); Martić and Savić (2001); and Cuffaro and Vassallo (2002).
} 
difference in efficiency change due to difference in sources of customers and management styles.

Anderson et al. (1999a) proposed an evaluation of managerial efficiency levels in the hotel industry by using the stochastic frontier technique.

An overview of efficiency analysis on the restaurant industry can be found in Reynolds (2003). For other applications on efficiency measure at micro level in tourism field, see Baker and Riley (1994); Bell and Morey (1995); Anderson et al. (1999b); Barros (2004); Barros (2005); and Barros and Mascarenhas (2005).

The present work intends to enlarge the economics of tourism in this specific aspect focussing on destination competitiveness and providing a measure of competitiveness at regional level by means of the above mentioned efficiency concept. Unlike most applications of efficiency measurement where the observations considered are related to the public sector (like hospitals, schools, etc.), private firms or plants, our analysis aims to assessing the economic efficiency of territorial areas, viz. tourist destinations. Thus, the tourist region is seen as a territorial industry.

Using parametric (Stochastic Production Frontier) and non-parametric (Data Envelopment Analysis, DEA) methods, this paper aims to assess production frontiers and efficiency coefficients of alternative tourist destinations; these statistical tools are applied to the 103 Italian regions for the year 2001. Moreover, according to previous empirical studies, a comparison between the two frontier efficiency methods is made (Sharma et al. 1997; Cummins and Zi, 1998; Murillo-Zamorano and Vega-Cervera, 2001). For the purpose of this paper, we limit our analysis to technical efficiency. A Cobb-Douglas stochastic frontier production function and constant returns to scale output-oriented DEA models are estimated.

The paper is structured as follows. Section 2 contains a concise description of the destination competitiveness concept. Then, Section 3 presents, synthetically, a description of production frontier analysis. In Section 4, the data base and the empirical findings are presented and discussed. Section 5 concludes with some retrospective and prospective remarks.

\section{Tourist Destination Competitiveness: the Crouch and Ritchie Model}

Tourist areas seek to exploit their locational attractiveness by a smart use of input factors. This paper investigates the technically efficient utilisation of tourist resources in a set of tourist destinations, and considers this as a proxy for the concept of destination competitiveness. What do we mean by 'competitiveness'? What is 'destination competitiveness'? And, what are the strategic factors determining destination competitiveness? 
The concept of competitiveness can seem easy to understand - it is the expression of the qualitative and quantitative superiority of an actor (a firm, a territory, etc.) over the real and potential competitors set. However, the complexity of the concept is made evident when we seek to define and measure it, as is apparent from several literature sources. For example, Porter (1990) argues that its ambiguity stems from the wide variety of definitions and perspectives on competitiveness, which makes it difficult to give an exhaustive or undisputed definition. Scott and Lodge (1985) connect, for instance, this complexity to the multidimensional and relative nature of the concept of competitiveness. The versatile nature of competitiveness concerns its essential qualities, while the relative aspect deals with the concept of superiority - but superior in comparison to what and to whom?

These considerations have led to a proliferation of definitions of competitiveness over the years (e.g. Scott and Lodge, 1985; Crouch and Ritchie, 1999, 2000; OECD, 1994; and Newall, 1992). In 1999, Crouch and Ritchie developed a conceptual model on tourism destination competitiveness built on Porter's 'diamond of national competitiveness' model (1990). The national diamond model identifies six elements on which competition between national industries - or destinations, in the case of tourism - is based. These elements are: factor conditions; demand conditions; related and supporting industries; firm strategy, structure, and rivalry; chance events; and government.

Using Porter's model, Crouch and Ritchie (CR) have defined a conceptual model of tourist competitiveness. The model identified two distinct and interrelated environments: micro and macro, respectively. The micro-environment concerns the details of the tourist destination and travel to it which have to be compared with the competitors. In other words, it includes "members of the travel trade (i.e. tour packagers, suppliers, retail travel agents, specialty channelers, and facilitators), tourism markets, competitive destinations, and a destination's public or stakeholders (resident of the destination, employees of the tourism and hospitality industry, citizen-action groups, the media, financial and investment institutions, relevant government departments, and immediate neighbourhoods)" (Crouch and Ritchie, 1999, p. 146). The macro-environment concerns the elements outside the micro-environment but nevertheless influencing it. These elements are: increasing attention for the natural environment; the economic restructuring of economies that is occurring worldwide; the shifting demographics of the marketplace; the increasingly complex technology-human resource interface, etc.

According to the authors, the micro- and macro-environment affect simultaneously the 'competitiveness core' defined by four major components: "core resources and attractors (physiography, culture and history, market ties, mix of activities, special events, entertainment and superstructure); supporting factors and resources (infrastructure, accessibility, facilitating resources, hospitality, enterprise); destination management (resources stewardship, marketing, finance and venture capital, organization, human resource development, 
information/research, quality of service, visitor management); and qualifying determinants (location, interdependencies, safety/security, awareness/image/brand, cost/value)" (Crouch and Ritchie, 1999, pp. 146-147).

Upstream and downstream of CR's model, we find the concept of comparative and competitive advantage. The former concerns the "endowment resources" of the destination area: human, physical, knowledge, and capital resources; infrastructure and tourism superstructure; historical and cultural resources. The latter concerns the "resources deployment": audit and inventory, maintenance, growth and development, efficiency and effectiveness $^{2}$ (Crouch and Ritchie, 1999, pp. 142-144).

To sum up, CR's model shows many different elements on which competition between tourist destinations is based. Therefore, achieving a superior performance and position in the market depends on the capability of a destination to manage and organize its resources according to a systematic logic, i.e., in an efficient way, so as to maximize the performance on the competitive tourist market. In the light of the above considerations and according to the competitive advantage concept, the present paper provides a measure of site efficiency that represents an assessment of destination competitiveness. In particular, we will provide a measurement of competitiveness in terms of efficiency that, according to Crouch and Ritchie, is a critical aspect of competitive advantage of destinations. In other words, using the metaphor of the territory as a firm, we hypothesize that the resources (material and human) in a certain territory constitute the input of a 'virtual production process', the output of which is tourist flows. In the light of this, destination tourist performance can be evaluated by the capability of a territory to transform its stock resources into maximum production. That is to say, productive efficiency of a territory to produce tourist flows can be viewed as a proxy for destination competitiveness. For our aim, we use the theoretical background of production frontier analysis - generally used to evaluate the efficiency of firms or non-profit organizations - in order to assess empirically production frontiers and efficiency coefficients for tourist destinations.

\section{Production Frontier Analysis}

\subsection{Introduction}

In this section the methodology and the models used in our study will be presented. Efficiency can be evaluated by fitting a production (this is our case) or cost frontier. The (in)efficiency can then be assessed as the deviation of the actual production process from a

\footnotetext{
${ }^{2}$ See Cracolici $(2004,2005)$ and Cracolici and Nijkamp (2006) for a competitiveness measure in terms of efficiency and effectiveness.
} 
standard optimal process. If $\mathbf{Y}$ indicates the possible set of production processes, given a technology:

$$
\mathbf{Y}=\{(\boldsymbol{y}, \boldsymbol{x}) / \boldsymbol{y}\}
$$

where $\boldsymbol{y}$ is the output vector that can be produced from the input vector $\boldsymbol{x}$; then, a process is efficient when it is not possible to obtain the same output $(y)$ with less inputs. The set of efficient processes defines the frontier function that gives the maximum possible output, given the inputs. Any output below the optimal output is inefficient, given the input set.

There are different statistical techniques to evaluate the production frontier in economic analysis: parametric and non-parametric, respectively. In the first group of techniques we find the Non-statistic Deterministic Frontier Function (Aigner and Chu, 1968); the Statistic Deterministic Frontier Function (Afriat, 1972); and the Stochastic Frontier (for details see, Aigner et al., 1977; and Meeusen and Van de Broeck, 1977). In the second group, we find Data Envelopment Analysis (Charnes et al., 1978; and Banker et al., 1984) and Free Disposal (Deprins et al., 1984) ${ }^{3}$. For our aim, we use both a parametric and a non-parametric method to assess the frontier production, viz. data envelopment analysis (DEA) and the stochastic production frontier (SPF) function. Each method will be discussed briefly here. Although both methods are similar in terms of the way they determine a frontier and inefficiency based upon that frontier, there is also a significant difference. The DEA approach provides a 'measurement' of inefficiency (the 'Farrell approach'), while the SPF measures and explains the inefficiency (the 'Leibenstein approach') (Button and Weyman-Jones, 1994). The SPF explains output from an input set and a stochastic disturbance. The stochastic disturbance consists of two parts; a stochastic inefficiency, which can be instrumented, and a 'white noise' disturbance term. Whereas DEA assumes that the input set explains production and determines efficiency (or inefficiency) using the distance to the production frontier, SPF considering a stochastic deviation is more flexible. SPF determines the efficiency as the distance to the production, but it also considers a stochastic deviation in output. For details on frontier techniques and their strength and weakness, we refer to Coelli (1995), Førsund and Lovell (1980); Bauer (1990); Bjurek et al. (1990); Seiford and Thrall (1990); Battese (1992); Bravo-Ureta and Pinheiro (1993); and Fried et al. (1993).

In the light of the above considerations, the main strength of the stochastic frontier approach is that it deals with stochastic noise. The need for imposing an explicit functional form for the underlying technology and an explicit distributional assumption for the inefficiency term are the main weaknesses of the stochastic frontier. The main advantage of the DEA approach over SPF is that it does not require any assumptions concerning the

\footnotetext{
${ }^{3}$ For details, see Førsund and Sarafoglou (2002).
} 
production technology ${ }^{4}$, while DEA can also easily accommodate multiple outputs. However, since DEA is deterministic and attributes all the deviations from the frontier to inefficiencies, a frontier estimated by DEA is likely to be sensitive to measurement errors or other statistical noise in the data. Given the different strengths and weaknesses of the two techniques, and considered the fact that there is no consensus on the best method for measuring the frontier efficiency; it is of interest to compare the empirical performance of the two techniques using the same data set.

\subsection{The Stochastic Frontier}

The stochastic production frontier is a parametric method that uses the distance to the production frontier to determine the economic efficiency. SPF has been introduced as a statistical approach by Afriat (1972) in order to deal with observation errors and possible bias corrections. The actual stochastic frontier production was first proposed by Aigner et al. (1977), and Meeusen and Van den Broeck (1977). Extensive statistical inference was made possible by the introduction of the composed error term in the parametric model. The original specification involved a production function for cross-sectional data which has an error term that has two components, one to account for random effects and another one to account for technical inefficiency. The stochastic production frontier has the following form:

$$
\begin{aligned}
& y_{j}=\beta x_{j}+\varepsilon_{j} \quad \mathrm{j}=1, \ldots, \mathrm{J}, \\
& \text { with } \varepsilon_{j}=\left(v_{j}-u_{j}\right),
\end{aligned}
$$

where $y_{j}$ is the production (or the logarithm of the production) of the $j$-th destination; $x_{j}$ is a $(1 \times \mathrm{K})$ vector of input quantities (or the logarithm of the input quantities) used by the $j$-th destination; $\beta$ is a $(\mathrm{K} \times 1)$ vector of unknown parameters. $v_{j} \sim \mathbf{N}\left(0, \sigma^{2}{ }_{v}\right)$ is the stochastic disturbance which is assumed to be i.i.d. and independent of the $u_{j}$, which is distributed according to a half normal distribution with $\sigma_{u}^{2}$. For $u_{j}>0$, a given destination $j$ does not reach the (efficiency) frontier. The technical efficiency $\theta_{j}$ of destination $j$ is then calculated as $\theta_{j}=\exp \left(-u_{i}\right)($ see Battese and Coelli, 1988).

Note that the stochastic frontier model in Eq. (2) can be extended to take into consideration the inefficiency $u_{j}$. The frontier model and the inefficiency model $u_{j}=u_{j}\left(z_{j}\right)$ are estimated simultaneously. Unfortunately, we do not have the necessary variables $z_{j}$ to explain the inefficiencies.

The original SPF specification has been applied in different empirical works, but it has also been altered and extended in a number of ways. These extensions concern the distributional assumptions for $\mathrm{u}_{j}$; the use of panel data; the extension of the methodology to

\footnotetext{
${ }^{4}$ The only assumption is that the production possibility set is convex.
} 
cost functions; the estimation of systems of equations, and the introduction of control variables to explain the inefficiency. For details we refer to Førsund et al. (1980); Schmidt (1986); Bauer (1990); Battese and Coelli (1992); Greene (1993); and Battese and Coelli (1995).

The main problem with the stochastic model is that there is no 'a priori' justification for the selection of any particular functional form for the frontier function and the distributional form for the non-negative error term.

In our analysis, the model explaining the tourist flows (national and international bednights) was specified in logs and we assume a half normal distribution of the error term $u_{j}$, with mean $m$ and constant variance. The empirical results obtained by the Frontier software (Coelli, 1996) will be discussed in Section 4.

\subsection{Data Envelopment Analysis}

DEA is a non-parametric linear programming method of measuring efficiency to assess a production frontier. The efficiency of each tourist destination is evaluated against this frontier. In other words, the efficiency of a destination is evaluated in comparison with the performance of other destinations.

DEA is based on Farrell's (1957) original work, further elaborated by Charnes et al.'s (1978) CCR model, and Banker et al.'s (1984) BCC Model. It has been widely used in empirical efficiency analysis, because it does not require an assumption about the functional form, and it can be used in cases where the units (Decision-Making Units, DMUs ${ }^{5}$ ) use multiple inputs to produce multiple outputs.

Generally, DEA can be applied to efficiency problems in public sector agencies (e.g., schools, hospitals, airports, courts, etc.) and private sector agencies (banks, hotels, etc). Our analysis aims at assessing the tourist efficiency of destination areas in Italy. As argued above, we will use data for one output and three inputs, in order to estimate how well regions in Italy utilize their tourist resources. For this purpose, we adopt an output-oriented constant returnsto-scale DEA model (CCR Model) for each region in 2001. We deploy such a model because our aim is to explore how well the regions in Italy deploy their input resources for tourism. In other words, given a stock of tourist resources, the aim is to maximize tourist flows.

DEA models determine efficiency as the distance to the frontier. The efficiency measure proposed by Charnes et al. (1978) maximizes efficiency in terms of the ratio of total weighted output to total weighted input, subject to the condition that, for every destination, this efficiency measure is smaller than or equal to 1 . Given $J$ destinations with $I$ inputs and $R$ outputs, the measure of efficiency of a destination $k$ can be specified as:

\footnotetext{
${ }^{5}$ By using the term DMU, Charnes et al. (1978) emphasize that their interest lies in the decisions made by nonprofit organizations rather than profit maximizing firms.
} 


$$
\begin{array}{ll}
\operatorname{Max}_{u, v} & \frac{\sum_{r=1}^{R} u_{r} y_{r k}}{\sum_{i=1}^{I} v_{i} x_{i k}} \\
\text { s.t. } & \frac{\sum_{r=1}^{R} u_{r} y_{r j}}{\sum_{i=1}^{I} v_{i} x_{i j}} \leq 1 ; \quad \text { for } \mathrm{j}=1, \ldots, \mathrm{J} \\
& v_{i}, u_{r} \geq 0,
\end{array}
$$

where $x_{i j}$ is the amount of input $i$ to destination $j ; y_{r j}$ the amount of output $r$ from destination $j$; $u_{r}$ the weight given to output $r$; and $v_{i}$ the weight given to input $i$.

The maximization problem in (4) can have an infinite number of solutions. Charnes et al. (1978) show that the above fractional programming problem has the following equivalent linear programming formulation, which avoids this problem:

$$
\begin{aligned}
\operatorname{Max}_{u, v} & \sum_{r=1}^{R} u_{r} y_{r k} \\
\text { s.t. } & \sum_{i=1}^{I} v_{i} x_{i j}-\sum_{r=1}^{R} u_{r} y_{r j} \geq 0 ; \quad \text { for } \mathrm{j}=1, \ldots, \mathrm{J}, \\
& \sum_{i=1}^{I} v_{i} x_{i k}=1 ; \\
& u_{r} \geq 0 ; \quad \text { for } \mathrm{r}=1, \ldots, \mathrm{R}, \\
& v_{i} \geq 0 ; \quad \text { for } \mathrm{i}=1, \ldots, \mathrm{I} .
\end{aligned}
$$

The dual specification of this linear programming model can be written as follows:

$$
\begin{aligned}
& \operatorname{Min}_{\theta, \lambda} \theta_{k} \\
& \text { s.t. } \sum_{j=1}^{J} \lambda_{j} y_{r j} \geq y_{r k} ; \text { for } \mathrm{r}=1, \ldots, \mathrm{R}, \\
& \theta_{k} x_{i k}-\sum_{j=1}^{J} \lambda_{j} x_{i j} \geq 0 ; \text { for } \mathrm{i}=1, \ldots, \mathrm{I}, \\
& \quad \lambda_{j} \geq 0 ; \text { for } \mathrm{j}=1, \ldots, \mathrm{J} .
\end{aligned}
$$

The destination, $j$, is efficient, if $\theta^{*}=1$, where an asterisk to a variable denotes its optimal 
solution. If this condition is not satisfied, the destination $j$ is inefficient $\left(\theta^{*}>1\right)$.

The efficiency coefficient can be either output-oriented (as in Eq. (5)) or input-oriented. If the output-oriented coefficient is greater than 1 in Eq. (5), it is possible to increase all outputs keeping the inputs constant. Likewise, if the input coefficient is smaller than 1 , it is possible to reduce the inputs keeping the outputs constant. Besides, the DEA model can be different in the assumption on returns-to-scale (constant or variable).

As mentioned, we will use an output-oriented constant returns-to-scale DEA model (CCR Model) for each tourist area. In Section 4 the DEA results, obtained by the EMS software (Scheel, 2000), will be presented and discussed.

\section{Data And Results}

We have argued above, that from a industrial business point of view, we will treat a region in the same way as a company, so that a tourist area should manage its scarce inputs efficiently; in other words, the region's physical and human resources form the input of a virtual tourist 'production process', and the output is made up by such factors as arrivals, bednights, value added, employment, customer satisfaction, etc. As a consequence, tourism destination performance, that reflects the competitiveness at territorial level, can be evaluated through a measurement of efficiency. In view of all these considerations, the following 'production function' for tourism is proposed:

$$
\text { Tourist output }=\mathrm{f} \text { (material capital, human capital, labour) }
$$

Tourist output is evaluated here by a non-financial measure, viz. bed-nights (BN) relative to population. In light of the destination concept and the site choice as well as the availability of data, the following proxies for cultural and historical capital, human capital and labour in our study were chosen: the regional state-owned cultural patrimony and heritage $(\mathrm{CPH})$ (number of museums, monuments and archaeological sites) standardized for population; tourist school graduates divided by working age population (TSG); and the labour units (ULAs) employed in the tourism sector divided by the total regional $\mathrm{ULA}^{6}$. We tried to include in the production function the number of beds in hotels and in complementary

\footnotetext{
${ }^{6}$ Data on output has been obtained from ISTAT (National Statistics Institute) (2001a), while the data on inputs has been obtained from different sources: provincial state-owned cultural patrimony and heritage (number of museums, monuments and archaeological areas) from the Ministry of Cultural Heritage (2001); tourist school graduates from the Ministry of Education; and labour units (ULA) employed in the tourism sector from ISTAT (2001b). Because the statistics from the Ministry of Cultural Heritage do not supply the data of regions and provinces with special statute status (Sicily, Aosta, Trento and Bolzano), for these data we have used as a proxy for cultural heritage the region and province-owned cultural heritage (museums, monuments and archaeological areas) (2001) supplied by the Regional and Provincial Bureaus of Cultural Heritage. Finally, ULA includes the following economic sectors: commerce, repairs, hotels, restaurants, transport and communication. If the indirect impact of tourism on commerce and repairs is considered, any error with this variable may be neglected.
} 
accommodations as proxy of material capital. The significant value of the Hausman test highlighted an endogeneity problem for these variables - leads us to no consider these variables in the present application, and points to the need to do future research in order to estimate a structural model.

Moreover, though, the regional state-owned cultural patrimony and heritage is a contextual variable, it cannot be neglected the correlation between this and provincial bednigths; i.e. we explicitly link output and artistic patrimony in the production function. Artistic patrimony is a determining factor, an attractor or core resource in a destination's tourist development, which together with other variables such as accommodation facilities, food services, transportation facilities, quality of destination management organization account for the differences in competitiveness levels, viz. in the ability of destination to attract tourist flows (Crouch and Ritchie, 1999, 2000).

According to earlier studies on production function, in the present study a quasiproduction function has been considered in which competitiveness disparities are accounted for by cultural and historical capital, human capital and labour (Aschauer, 1989; Biehl, 1986; and Cutanda and Paricio, 1994).

Table 1 gives a summary description of input and output variables and highlights that there are not strong disparities in each of the inputs considered, whereas the output variable shows greater variability.

$<<$ Table 1 about here >>

Table 2 shows the estimation results obtained by a cross-section estimation based on stochastic frontier analysis with regard to the 103 Italian regions for the year 2001. A simple Cobb-Douglas specification was used for the production function, while the half-normal distribution was used for the inefficiency error ${ }^{7}$.

$<<$ Table 2 about here >>

In our empirical analysis presented in Table 2 all variables appear to be significant. It should however, also be noted that the ULAs are strongly significant; this can be due to the fact that labour units do not only include the tourist sector. $\sigma^{2}$ is the sum of the variances of the two error terms, i.e., the 'standard' error term, $v_{j}$, and the non-negative deviation, $\mathrm{u}_{j}$, from the frontier. $\gamma$ is the variance of the deviation from the frontier $\left(\sigma_{u}^{2}\right)$ over the sum of the variances of the two error terms $\left(\sigma^{2}=\sigma^{2}{ }_{v}+\sigma^{2}{ }_{u}\right)$. Since $\gamma$ is statistically equal to 0.77 , we can conclude that there is a highly significant 'efficiency effect'. The efficiency coefficients derived from this model are presented in Table 3, together with the efficiency scores from the

\footnotetext{
${ }^{7}$ A different error distribution was used, but no significant differences were obtained in the parameter estimates.
} 
DEA. The DEA analysis - based on the output-oriented constant returns-to-scale model addresses the same 103 Italian regions for the year 2001 and the same output and input variables.

$<<$ Table 3 about here >>

The technical efficiency score, from the stochastic frontier, varies between 15 percent (Reggio Calabria) to 85 percent (Teramo), while the average efficiency score is 0.56 . Artistic and cultural destinations seem to be more efficient or competitive than destinations with a prevalent coastal function (e.g., Verona, Siena, Pisa, Ravenna, etc). This can be due to the input used as a proxy for contextual variable that is hedged by availability of data, i.e., likely different types of inputs (natural, cultural, artistic and environmental resources) are required to produce different output or site tourist profiles (artistic, coastal, mountain, business area). From the DEA results it appears that only 7 regions are efficient; the average technical efficiency is equal to 0.29 . Among the regions with a high efficiency score we find traditional tourist destinations (i.e., Rimini, Oristano, Trento, Bolzano, Venice and Siena).

In the literature, generally the results from the two methods are comparable, although the efficiency coefficients are, of course, not equal, due to the different nature of the two models. There are, however, some differences with regard to Bolzano, Venice, Rimini and Oristano. In general, the efficiency coefficient from the DEA model is lower than the stochastic frontier analysis. The Spearman correlation coefficient between the two alternative efficiency measures is equal to 0.63 ; the standard deviation is higher $(0.28)$ for DEA efficiency scores than SPF scores (0.17). These results, according to earlier studies, point to a low consistency between the two methods; viz. the DEA scores are inferior in value to SPF scores and the ranking is not preserved (see also, Cummins and $\mathrm{Zi}, 1998$; and Bauer et al., 1998).

The difference between the two methods is mainly evident with regard to cultural and business areas, which usually perform much worse under the DEA frontier. This can be due to the fact that the DEA frontier is piecewise linear, while the parametric frontier is a fitted curve, and thus more precise. Besides, a DEA assumes that the input set fully explains the production frontier, so that the coefficients depend strongly on the data. Many destinations with a prevalent artistic tourist profile (i.e., high cultural heritage) do not have a high efficiency coefficient in the case of our DEA model; this can be interpreted by an overendowment of inputs (specifically in order to cultural and historical capital) in relation to their production of tourist flows and their 'key competitors'.

In brief, Stochastic and DEA frontier models show that technical efficiency varies greatly between Italian regions, the regions with a bad performance or efficiency score less than the average efficiency score are $43.0 \%$ in the DEA model and $64.0 \%$ in the SPF model. Several hypotheses can be advanced for the inefficient use of the inputs in order to produce the 
maximum possible output. The reason may be that too many (or few) inputs are used thus an imbalance between inputs and outputs exists. This can be caused by various deficiencies. Destination management organizations do not know which should be the phase of the tourist destination life-cycle (e.g., growth, maturity and etc.) thus they may be unable to adopt the correct strategy. Moreover, uncontrollable factors or unexpected events can be causes of technical inefficiency.

The empirical results - from the DEA frontier and the stochastic model - show that more inputs than those considered are necessary to analyze and identify the destination tourist profile. Future research, using other variables such as a proxy of the environment in a broad sense and/or the analysis of destination clusters, may shed more light on these considerations. Moreover, with respect the previous aspect, an efficiency analysis for homogenous tourist profile of the regions can be done. Finally, other different parametric and non- methods can be used to assess the competitiveness or the efficiency of Italian tourist destination, and to improve both the tourism economics in this specific aspect and the comparative analysis among efficiency methods (e.g., DEA with variable returns-to-scale, Free Disposal Hull method, etc.).

\section{Conclusion}

In recent years, the destination tourist performance, the destination competitiveness and its measurement have increasingly obtained attention in the tourism literature. In fact, over the last few years, tourism has become an important economic activity with significant positive economic effects, especially because it is currently 'en vogue' to escape from the home environment and to relax by finding new, unusual and remote places to visit.

All this has prompted DMOs to plan and develop tourism policies based on strategies and operating actions that create an advantage over their competitors. As a consequence, it has become a very important research task to measure the performance of each area against its 'key competitors' in order to identify proper strategic actions needed to maintain or strengthen its position as market leader.

In spite of these needs, only limited empirical research - based on micro and qualitative data - is available in the literature (e.g. Kozak and Rimmington, 1999; and Kozak, 2002), while an example of Destination Competitiveness Analysis by quantitative data is supplied by Alavi and Yasin (2000).

In the light of these considerations, we present in our study the results of a statistical approach of the possibility of evaluating the tourist performance (viz. tourist competitiveness) and measurement of the efficiency of Italian tourist destinations. It is an evaluation analysis of tourist performance by quantitative and macro-data.

For our purpose, Stochastic and Data Envelopment Analysis Frontier models were applied 
in order to evaluate the tourist efficiency or competitiveness of different regions in Italy.

Tourism regions were regarded in our study as competing industries. We applied the two different methods to the 103 Italian regions, for the year 2001, using one output and three inputs.

In this paper, frontier estimations and efficiency coefficients for Italian regions have been presented. Stochastic and DEA frontier models show that technical efficiency varies greatly between Italian regions. The stochastic frontier indicates that artistic and cultural destinations perform better than destinations with a coastal or mountainous function. The DEA results show a low average technical efficiency $(0.29)$ and only 7 regions have an efficiency score equal to 1 . In contrast to the stochastic frontier analysis, cultural and artistic destinations perform much worse under the DEA frontier (e.g., Verona, Ravenna, Florence, Rome, Syracuse, etc.).

The comparison between the results of the two methods shows that efficiency coefficients from the DEA frontier are usually relatively lower than the stochastic frontier coefficients. Although the efficiency coefficients are, of course, not equal - due to the different nature of the two methods -, a comparative analysis of DEA and frontier results, - addressing the contrasting results from the two methods - shows that these differences are probably depending on the lack of homogeneity in the set of the regions under consideration. In our view, the different tourist functions among the Italian destinations are not well captured by the input variables considered here. This lack of homogeneity is more highlighted by DEA, because, as well known, this method is more sensitive to data than a stochastic frontier analysis (see Coelli et. al. 1998).

The general conclusion following from the inefficiency of the majority Italian regions with regards to DEA and SPF methods - is that local destination management organizations (DMOs) must work hard in order to improve the tourist performance of Italian destinations focussing attention on the balance inputs/outputs.

These results indicate important directions for further research. For instance, additional information on accommodation and natural resources should allow us to obtain and verify the above assumption on the lack of homogeneity in the set of the regions under consideration.

In conclusion, with a DEA and stochastic frontier analysis, we have found an appropriate way of treating different indicators on the 'supply side' to explain how the regions transform their resources into tourist flows. It turns out that the best way to manage the various indicators is to insert them into a well-defined theoretical background (i.e., the production function approach). Although many factors influence the levels and changes in tourist supply, we have underlined, using the available data, some relevant features of the production process of this particular 'product'. Finally, the not consistency between the rank from the two methods lead us to encourage the use of parametric and non-parametric methods in a complementary way. 


\section{References}

Afriat, S. (1972) Efficiency Estimation of Production Functions, International Economic Review, 13(3), 568-598.

Aigner, D., Chu S.F. (1968) On Estimating the Industry Production Function, American Economic Review, 58, 226-239.

Aigen, D. J., Lovell, C.A.K., Schmidt, P. (1977) Formulation and Estimation of Stochastic Frontier Production Function Model, Journal of Econometrics, 6(1), 21-37.

Alavi, J., Yasin, M.M. (2000) A Systematic Approach to Tourism Policy, Journal of Business Research 48(2), 147-156.

Anderson, R.I., Fish, M., Xia, Y., Michello, F. (1999a) Measuring Efficiency in the Hotel Industry: A Stochastic Frontier Approach, International Journal of Hospitality Management, 18(1), 45-57.

Anderson, R.I., Lewis, D., Parker, M.E. (1999b) Another Look at the Efficiency of Corporate Travel Management Departments, Journal of Travel Reasearch, 37(3), 267-272

Aschauer, D. (1989) Is Public Expenditure Productive?, Journal of Monetary Economics 23: 177-200.

Banker, R.D., Charnes, A., Cooper, W.W. (1984) Some Models of Estimating Technical and Scale Inefficiencies in Data Envelopment Analysis, Management Science 9(9), 10781092.

Banker, M., Riley, M. (1894) New Perspectives on Productivity in Hotels: some Advances and New Directions, International Journal of Hospitality Management, 13(4), 297-311.

Barros, C.P. (2004) A Sthocastic Cost Frontier in the Portuguese Hotel Industry, Tourism Economics, 10, 177-192.

Barros, C.P. (2005) Measuring Efficiency in the Hotel Sector, Annals of Tourism Research, 32(2), 456-477.

Barros, C.P., Mascarenhas, M.J. (2005) Technical and Allocative Efficiency in Chain of Small Hotels, International Journal of Hospitality Management, 24, 415-436.

Battese, G.E., Coelli, T.J. (1988) Prediction of Firm-level Technical Efficiencies with a Generalized Frontier Production Function and Panel Data, Journal of Econometrics, 38, 387-399.

Battese, G.E., Coelli, T.J. (1992) Frontier Production Functions, Technical Efficiency and Panel Data: with Application to Paddy Farmers in India, Journal of Productivity Analysis, 3, 153-169.

Battese, G.E. (1992) Frontier Production Functions and Technical Efficiency: A Survey of Empirical Applications in Agricultural Economics, Agricultural Economics, 7, 185-208.

Battese, G.E., Coelli, T.J. (1995) A Model for Technical Inefficiency Effects in a Stochastic Frontier Production Function for Panel Data, Empirical Economics, 20, 325-332.

Bauer, P.W. (1990) Recent Developments in the Econometrics estimation of Frontiers, Journal of Econometrics, 46, 39-56.

Bauer, P.W., Berger, A.N., Ferrier, G.D., Humphrey, D.B. (1998) Consistency Conditions for Regulatory Analysis of Financial Institutions: A Comparison of Frontier Efficiency Methods, Journal of Economics and Business, 50, 85-114.

Bell, J., Morey, R.C. (1995) Increasing the Efficiency of Corporate Travel Management through Macro-benchmarking, Journal of Travel Research, 33(3), 11-20.

Biehl, D. (eds.) (1986) The Contribution of Infrastructure to the Regional Development, Commission of the European Communities, Brussels. 
Bjurek, H., Hjalmarsson, L., Førsund, F.R. (1990) Deterministic Parametric and Nonparametric estimation in Service Production, Journal of Econometrics, 46, 213-227.

Bravo-Ureta, B.E., Pinheiro, A.E. (1993) Efficiency Analysis of Developing Country Agriculture: A Review of Frontier Function, Agricultural and Resource Economics Review, 22, 88-101.

Button, K.J., Weyman-Jones, T.G. (1994) X-efficiency and Technical Efficiency, Public Choice, 80, 83-104.

Charnes, A., Cooper W.W., Rhodes, E. (1978) Measuring the Efficiency of Decision Making Units, European Journal of Operational Research, 2(6), 429-444.

Charnes, A., Cooper W.W., Li S. (1989), Using Data Envelopment Analysis to Evaluate Efficiency in the Economic Performance of Chinese Cities, Socio-Economic Planning Sciences, 23(6), 325-344.

Coelli, T.J. (1995) Recent Developments in Frontier Modeling and Efficiency Measurement, Australian Journal of Agricultural Economics, 39, 219-245.

Coelli, T.J. (1996) A Giude to FRONTIER Version 4.1: A Computer Program for Stochastic Frontier Production and Cost Function Estimation, CEPA Working Paper 96/07, Department of Econometrics, University of New England, Armidale, Australia.

Coelli, T. J., Rao, D.S.P., Battese G. E. (eds.) (1998) An Introduction to Efficiency and Productivity Analysis, Kluwer Academic Publishers, USA.

Cracolici, M.F. (2004) Tourist Performance Evaluation: a Novel Approach, Atti XLII Riunione Scientifica della Società Italiana di Statistica, June 2004, Bari.

Cracolici, M.F. (2005) La Competitività tra Destinazioni Turistiche. Un’Analisi di Destination Benchmarking, PhD Dissertation, Faculty of Economics, University of Palermo, Italy.

Cracolici, M.F., Nijkamp, P. (2006) Competition among Tourist Destination. An Application of Data Envelopment Analysis to Italian Provinces, in Giaoutzi M. and Nijkamp P. (eds.), Tourism and Regional Development: New Pathways, Ashgate, Aldershot, UK, forthcoming.

Crouch, G.I., Ritchie, J.R.B. (1999) Tourism, Competitiveness, and Societal Prosperity, Journal of Business Research, 44, 137-152.

Crouch, G.I., Ritchie J.R.B. (2000) The Competitive Destination: A Sustainability Perspective, Tourism Management, 21, 1-7.

Cuffaro, M., Vassallo, E. (2002), Sviluppo Economico e Sviluppo Umano: una Nota sulla Classificazione ONU di Alcuni Paesi, Scritti di Statistica Economica, 10.

Cummins, J.D., Zi, H. (1998) Comparison of Frontier Efficiency methods: An application to the U.S. Life Insurance Industry, Journal of Productivity Analysis, 10, 131-152.

Cutanda, A., Paricio, J. (1994) Infrastructure and Regional Economic Growth: The Spanish Case, Regional Studies, 28(1), 69-77.

Deprins D., Simar J., Tulkens, H. (eds.) (1984) Measuring Labor-Efficiency in Post Officies in The Performance of Public Enterprises: Concepts and Measurement, Tulkens H., North-Holland, Amsterdam.

Farrell, M. J. (1957) The Measurement of Productive Efficiency, Journal of the Royal Statistical Society, 120, 211-281.

Førsund, F.R., Lovell C.A.K., Schmidt, P. (1980) A Survey of Frontier Production Functions and of Their relationship to Efficiency Measurement, Journal of Econometrics, 13, 5-25.

Førsund F. R., Sarafoglou, N. (2002) On the Origins of Data Envelopment Analysis, Journal of Productivity Analysis, 17, 23-40.

Fried, H.O., Lovell C.A.K., Schmidt, S.S. (eds.) (1993) The Measurement of Productive Efficiency: Techniques and Applications, Oxford University Press, New York. 
Greene, W.H. (1993) The Econometric approach to Efficiency Analysis, in Fried, H.O., Lovell C.A.K. and Schmidt S.S. (eds.) The Measurement of Productive Efficiency: Techniques and Applications, Oxford University Press, New York, 68-119.

Hwang S., Chang, T. (2003) Using Data Envelopment Analysis to Measure Hotel Managerial Efficiency Change in Taiwan, Tourism Management, 24, 357-369.

ISTAT (2001a) Statistiche del Turismo, ISTAT, Roma.

ISTAT (2001b) Dati di Contabilità Nazionale, ISTAT, Roma.

Kozak, M., Rimmington, M. (1999) Measuring Tourist Destination Competitiveness: Conceptual Considerations and Empirical Findings, Hospitality Management, 18(3), 273283.

Kozak, M. (2002) Destination Benchmarking, Annals of Tourism Research, 29(2), 497-519.

Macmillan, W.D. (1986), The Estimation and Applications of Multi-regional Economic Planning Models Using Data Envelopment Analysis, Papers of the Regional Science Association, 60, 41-57.

Martić, M., Savić, G. (2001), An Application of DEA for Comparative Analysis and Ranking of Regions in Serbia with Regard to Social-Economic Development, European Journal of Operational Research, 132, 343-356.

Meeusen, W., and van den Broeck, J. (1977) Efficiency Estimation from Cobb-Douglas Production Functions with Composed Errors, International Economic Review, 18, 435444.

Morey, R.C., Dittman, D.A. (1995) Evaluating a Hotel GM's Performance: A case Study in Benchmarking, Cornell Hotel Restaurant and Administration Quarterly, 36(5), 30-35.

Murillo-Zamorano, L.R., Vega-Cervera, J.A. (2001) The Use of Parametric and Nonparametric Frontier Methods to Measure the Productive Efficiency in the Industrial Sector: A Comparative Study, International Journal of Production Economics, 69, 265275.

Newall, J.E. (1992) The Challenge of Competitiveness, Business Quarterly, 56.

OECD (1994) The World Competitiveness Report, World Economic Forum and IMD International, Lausanne, Switzerland.

Porter, M.E. (1990) The Competitive Advantage of Nations, The Free Press, New York.

Prosser, R. (1994) Societal Change and Growth, in Carter E. and Lowman G. (eds), Alternative Tourism, Ecotourism a Sustainable Option?, John Wiley \& Sons, Chichester, 89-107.

Reynolds, D. (2003) Hospitality-productivity Assessment: Using Data-envelopment Analysis, Cornell Hotel Restaurant and Administration Quarterly, 44(2), 130-137.

Scheel, H. (2000) Efficiency Measurement System, version 1.3.

Schmidt, P. (1986) Frontier Production Functions, Econometric Review, 4, 289-328.

Scott, B.R., Lodge, G.C. (1985) U.S. Competitiveness in the World Economy, Harvard Business School Press, Boston.

Seiford, L.M., Thrall, R.M. (1990) Recent Developments in DEA: The Mathematical Programming Approach to Frontier Analysis, Journal of Econometrics, 46, 7-38.

Sharma, K. R., Leung, P., Zaleski, H.M. (1997) Productive Efficiency of the Swine Industry in Hawaii: Stochastic Frontier vs. Data Envelopment Analysis, Journal of Productivity Analysis, 8, 447-459.

Susiluoto, I., Loikaanen, H. (2001), The Economic Efficiency of Finnish Regions 1988-1999: An Application of the DEA Method, 41st Congress of the European Regional Science Association, 29 August-1 September 2001, Zagreb, Croatia. 
Table 1 Characteristics of the inputs and outputs (2001)

\begin{tabular}{ccc}
\hline Variables & Mean & S.D. \\
\hline Input & & \\
CPH & 0.0016 & 0.0052 \\
TSG & 0.0949 & 0.0507 \\
ULA & 27.0012 & 4.5943 \\
Output & & \\
BN & 742.0036 & 989.0819 \\
\hline
\end{tabular}

Table 2 The stochastic frontier results for Cobb-Douglas function of 103 Italian tourist regions (2001)

\begin{tabular}{lcc}
\hline Variables $^{*}$ & $\begin{array}{c}\text { Parameter } \\
\text { estimate }\end{array}$ & t-value \\
\hline Constant & -8.0591 & -5.1205 \\
CPH & 0.1001 & 2.0311 \\
TSG & 0.1827 & 1.8677 \\
ULA & 4.8578 & 11.4547 \\
\hline$\sigma 2$ & 0.9533 & 3.5478 \\
$\gamma$ & 0.7742 & 4.7786 \\
log likelihood & -107.32 & \\
$*$ Variables are defined in the text &
\end{tabular}

* Variables are defined in the text 
Table 3 Estimated DEA efficiency coefficients for 103 Italian tourist regions (2001)

\begin{tabular}{|c|c|c|c|c|c|}
\hline Regions & $\begin{array}{c}\text { DEA } \\
\text { Results }\end{array}$ & $\begin{array}{c}\text { Stochastic } \\
\text { Frontier } \\
\text { Results }\end{array}$ & Regions & $\begin{array}{c}\text { DEA } \\
\text { Results }\end{array}$ & $\begin{array}{c}\text { Stochastic } \\
\text { Frontier } \\
\text { Results }\end{array}$ \\
\hline 1 Torino & 0.0592 & 0.3297 & 53 Pisa & 0.3221 & 0.7740 \\
\hline 2 Vercelli & 0.0471 & 0.4077 & 54 Arezzo & 0.1404 & 0.5894 \\
\hline 3 Biella & 0.0736 & 0.5323 & 55 Siena & 0.7753 & 0.8054 \\
\hline 4 Verbano-Cusio-Ossola & 0.4732 & 0.4838 & 56 Grosseto & 0.4537 & 0.4969 \\
\hline 5 Novara & 0.2724 & 0.6152 & 57 Perugia & 0.2892 & 0.6994 \\
\hline 6 Cuneo & 0.0581 & 0.4006 & 58 Terni & 0.1660 & 0.4875 \\
\hline 7 Asti & 0.0435 & 0.1530 & 59 Pesaro e Urbino & 0.3634 & 0.8072 \\
\hline 8 Alessandria & 0.0443 & 0.2422 & 60 Ancona & 0.2077 & 0.7166 \\
\hline 9 Aosta & 0.6581 & 0.6603 & 61 Macerata & 0.2290 & 0.6904 \\
\hline 10 Varese & 0.0644 & 0.4162 & 62 Ascoli Piceno & 0.4049 & 0.8081 \\
\hline 11 Como & 0.3901 & 0.5964 & 63 Viterbo & 0.0557 & 0.3443 \\
\hline 12 Lecco & 0.1079 & 0.6421 & 64 Rieti & 0.0579 & 0.6694 \\
\hline 13 Sondrio & 0.3227 & 0.5868 & 65 Roma & 0.2180 & 0.6662 \\
\hline 14 Milano & 0.1104 & 0.4334 & 66 Latina & 0.2746 & 0.6636 \\
\hline 15 Bergamo & 0.0622 & 0.5595 & 67 Frosinone & 0.1293 & 0.5723 \\
\hline 16 Brescia & 0.2404 & 0.7711 & 68 L'Aquila & 0.3037 & 0.4591 \\
\hline 17 Pavia & 0.0489 & 0.2622 & 69 Teramo & 1 & 0.8548 \\
\hline 18 Lodi & 0.0852 & 0.3372 & 70 Pescara & 0.0973 & 0.2837 \\
\hline 19 Cremona & 0.0274 & 0.3422 & 71 Chieti & 0.1185 & 0.5987 \\
\hline 20 Mantova & 0.0470 & 0.5211 & 72 Isernia & 1 & 0.7187 \\
\hline 21 Bolzano & 1 & 0.7044 & 73 Campobasso & 0.0935 & 0.5241 \\
\hline 22 Trento & 1 & 0.7780 & 74 Caserta & 0.0529 & 0.5110 \\
\hline 23 Verona & 0.6393 & 0.8054 & 75 Benevento & 0.0156 & 0.2164 \\
\hline 24 Vicenza & 0.1537 & 0.7682 & 76 Napoli & 0.1066 & 0.3622 \\
\hline 25 Belluno & 0.8048 & 0.8445 & 77 Avellino & 0.0249 & 0.2442 \\
\hline 26 Treviso & 0.0568 & 0.6306 & 78 Salerno & 0.2505 & 0.6964 \\
\hline 27 Venezia & 1 & 0.6962 & 79 Foggia & 0.2633 & 0.7399 \\
\hline 28 Padova & 0.3231 & 0.7108 & 80 Bari & 0.0285 & 0.2267 \\
\hline 29 Rovigo & 0.2498 & 0.7382 & 81 Taranto & 0.0367 & 0.5053 \\
\hline 30 Pordenone & 0.0779 & 0.7332 & 82 Brindisi & 0.0882 & 0.4501 \\
\hline 31 Udine & 0.5282 & 0.7200 & 83 Lecce & 0.1058 & 0.5564 \\
\hline 32 Gorizia & 0.9476 & 0.7817 & 84 Potenza & 0.0535 & 0.5273 \\
\hline 33 Trieste & 0.4250 & 0.3463 & 85 Matera & 0.1847 & 0.7645 \\
\hline 34 Imperia & 0.7400 & 0.5365 & 86 Cosenza & 0.1280 & 0.6837 \\
\hline 35 Savona & 1 & 0.6851 & 87 Crotone & 0.0952 & 0.5698 \\
\hline 36 Genova & 0.3015 & 0.3417 & 88 Catanzaro & 0.0917 & 0.6307 \\
\hline 37 La Spezia & 0.2328 & 0.4270 & 89 Vibo Valentia & 0.1857 & 0.4725 \\
\hline 38 Piacenza & 0.0827 & 0.2885 & 90 Reggio di Calabria & 0.0293 & 0.1457 \\
\hline 39 Parma & 0.1639 & 0.6572 & 91 Trapani & 0.0890 & 0.4525 \\
\hline 40 Reggio nell'Emilia & 0.1960 & 0.6807 & 92 Palermo & 0.0960 & 0.3963 \\
\hline 41 Modena & 0.1182 & 0.6537 & 93 Messina & 0.3737 & 0.5410 \\
\hline 42 Bologna & 0.1588 & 0.5591 & 94 Agrigento & 0.0920 & 0.3858 \\
\hline 43 Ferrara & 0.2299 & 0.6653 & 95 Caltanissetta & 0.4348 & 0.3697 \\
\hline 44 Ravenna & 0.4914 & 0.7399 & 96 Enna & 0.0351 & 0.2965 \\
\hline 45 Forli'-Cesena & 0.7004 & 0.7855 & 97 Catania & 0.1318 & 0.3595 \\
\hline 46 Rimini & 1 & 0.6447 & 98 Ragusa & 0.0940 & 0.5307 \\
\hline 47 Massa-Carrara & 0.2633 & 0.4734 & 99 Siracusa & 0.1072 & 0.7471 \\
\hline 48 Lucca & 0.2412 & 0.5586 & 100 Sassari & 0.4565 & 0.7072 \\
\hline 49 Pistoia & 0.3030 & 0.7476 & 101 Nuoro & 0.6783 & 0.7073 \\
\hline 50 Firenze & 0.4069 & 0.6979 & 102 Oristano & 0.8549 & 0.6501 \\
\hline 51 Prato & 0.0639 & 0.6278 & 103 Cagliari & 0.2978 & 0.4982 \\
\hline 52 Livorno & 0.6888 & 0.5503 & & & \\
\hline
\end{tabular}




\section{Tinbergen Institute}

The Tinbergen Institute is the institute for economic research of the Erasmus Universiteit Rotterdam, Universiteit van Amsterdam, and Vrije Universiteit Amsterdam.

Tinbergen Institute Amsterdam

Roetersstraat 31

1018 WB Amsterdam

The Netherlands

Tel.: $\quad+31(0) 205513500$

Fax: $\quad+31(0) 205513555$

Tinbergen Institute Rotterdam

Burg. Oudlaan 50

3062 PA Rotterdam

The Netherlands

Tel.: $\quad+31(0) 104088900$

Fax: $\quad+31(0) 104089031$

Most TI discussion papers can be downloaded at http:/ /www.tinbergen.nl. 